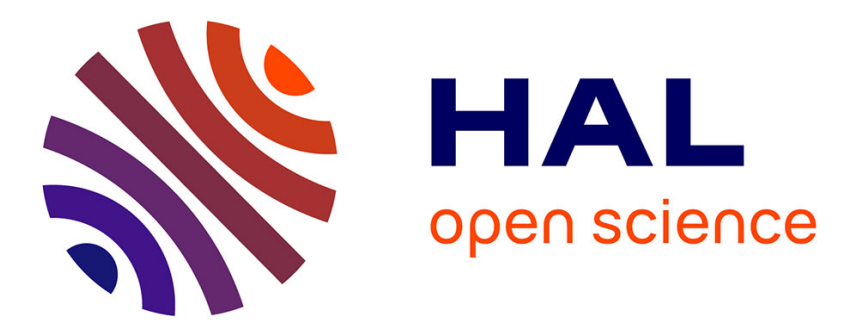

\title{
A microplasma process for hexagonal boron nitride thin film synthesis
}

\author{
H. Kabbara, S. Kasri, O. Brinza, G. Bauville, K. Gazeli, J. Santos Sousa, V. \\ Mille, A. Tallaire, G. Lombardi, C. Lazzaroni
}

\section{- To cite this version:}

H. Kabbara, S. Kasri, O. Brinza, G. Bauville, K. Gazeli, et al.. A microplasma process for hexagonal boron nitride thin film synthesis. Applied Physics Letters, 2020, 116 (17), pp.171902. 10.1063/1.5143948 . hal-02557411

\section{HAL Id: hal-02557411 \\ https://hal.science/hal-02557411}

Submitted on 11 Dec 2020

HAL is a multi-disciplinary open access archive for the deposit and dissemination of scientific research documents, whether they are published or not. The documents may come from teaching and research institutions in France or abroad, or from public or private research centers.
L'archive ouverte pluridisciplinaire HAL, est destinée au dépôt et à la diffusion de documents scientifiques de niveau recherche, publiés ou non, émanant des établissements d'enseignement et de recherche français ou étrangers, des laboratoires publics ou privés. 


\section{A microplasma process for hexagonal boron nitride thin film synthesis}

Cite as: Appl. Phys. Lett. 116, 171902 (2020); https://doi.org/10.1063/1.5143948

Submitted: 01 January 2020 . Accepted: 06 April 2020 . Published Online: 27 April 2020

H. Kabbara (D), S. Kasri, O. Brinza, G. Bauville, K. Gazeli (D), J. Santos Sousa (D), V. Mille, A. Tallaire (D), G. Lombardi, and C. Lazzaroni (iD)

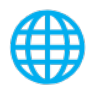

Lock-in Amplifiers
up to $600 \mathrm{MHz}$

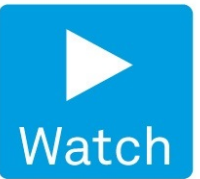




\title{
A microplasma process for hexagonal boron nitride thin film synthesis
}

\author{
Cite as: Appl. Phys. Lett. 116, 171902 (2020); doi: 10.1063/1.5143948 \\ Submitted: 1 January $2020 \cdot$ Accepted: 6 April 2020 . \\ Published Online: 27 April 2020
}

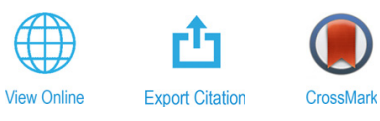

\author{
H. Kabbara, , ,a) (D S. Kasri, O. Brinza, ${ }^{7}$ G. Bauville, ${ }^{2}$ K. Gazeli, $^{2}$ (D) J. Santos Sousa, ${ }^{2}$ (D) V. Mille, ${ }^{7}$ A. Tallaire, \\ G. Lombardi,' and C. Lazzaroni ${ }^{1, b)}$ (D)
}

\author{
AFFILIATIONS \\ 'University Sorbonne Paris Nord, LSPM, CNRS, UPR 3407, F-93430 Villetaneuse, France \\ ${ }^{2}$ Université Paris-Saclay, CNRS, Laboratoire de Physique des Gaz et des Plasmas, 91405 Orsay, France \\ a)Electronic mail: hiba.kabbara@univ-lorraine.fr \\ b) Author to whom correspondence should be addressed: claudia.lazzaroni@lspm.cnrs.fr
}

\begin{abstract}
A process based on microplasmas generated in $\mathrm{Ar} / \mathrm{N}_{2}$ mixtures for nanomaterial synthesis is described in this Letter. The targeted material is hexagonal boron nitride (h-BN) that is in high demand for electronic and optoelectronic applications. The synthesis of high crystalline quality h-BN films over large areas still remains a challenge. In this study, a nanosecond pulsed high voltage is applied between two electrodes separated by a dielectric layer, with the whole system being drilled by a $400 \mu \mathrm{m}$ diameter hole (micro hollow cathode structure). This geometry allows for an efficient dissociation of $\mathrm{N}_{2}$ gas, a particularly important asset for the synthesis of nitride materials, which normally requires very high deposition temperatures $\left(\sim 1300^{\circ} \mathrm{C}\right)$. In this work, we report the growth of h-BN on 2 -in. silicon substrates at temperatures below $1000^{\circ} \mathrm{C}$, with a growth rate of about $30 \mathrm{~nm} / \mathrm{h}$, using this approach. The deposited films are characterized by Raman and electron energy loss spectroscopies and transmission electron microscopy to evaluate the phase purity, the quality, the surface morphology, and the crystallinity of the material. The films exhibit a stoichiometry very close to 1 with a crystalline domain size of about $3 \mathrm{~nm}$.
\end{abstract}

Published under license by AIP Publishing. https://doi.org/10.1063/1.5143948

Hexagonal boron nitride (h-BN) is a material of choice for electronic and optoelectronic applications, ${ }^{1,2}$ like gate dielectrics, due to its wide bandgap $(5.9 \mathrm{eV})$. Moreover, h-BN thin films exhibit thermal and chemical stabilities as well as a high compatibility with graphene, ${ }^{3,4}$ and as a consequence, $\mathrm{h}-\mathrm{BN}$ can be used as a complementary dielectric material in graphene-based electronics. ${ }^{5,6}$ This promising material can be synthesized by different processes: chemical vapor deposition, ${ }^{7}$ molecular beam epitaxy, ${ }^{8,9}$ atomic layer deposition, ${ }^{10}$ and ion implantation ${ }^{11}$ on various substrates (metals and semiconductors). However, a suitable method allowing the deposition of high crystalline quality layers on various and large-area substrates still remains to be developed.

In this paper, we present a process for the synthesis of h-BN based on the use of microplasmas. Microplasmas have received considerable attention since the early 2000s because of possible applications in several fields such as surface treatment, ${ }^{12}$ light sources, ${ }^{13}$ or nanomaterial synthesis. ${ }^{14}$ The interest of using microplasmas lies in the fact that they can be ignited with a large choice of electrical excitation (RF, DC, or pulsed DC) and generated at moderate and high pressures (up to atmospheric pressure) using very low values of applied voltage or injected power $(\sim 1 \mathrm{~W})$ compared to other nonthermal plasmas $(\sim 200 \mathrm{~W})$. In this study, a particular type of microplasma source is used, the Micro Hollow Cathode Discharge (MHCD) ${ }^{15}$ MHCDs are known to produce high electron densities, ${ }^{16,17}$ which is a favorable condition to optimize the dissociation of $\mathrm{N}_{2}$ molecules, a prerequisite for the synthesis of nitride materials at relatively low temperatures. The discharge is ignited in $\mathrm{Ar} / \mathrm{N}_{2}$ mixtures to produce atomic nitrogen, and the boron precursor used is boron tribromide $\left(\mathrm{BBr}_{3}\right)$, which is liquid at room temperature. The MHCD source alone (i.e., without the injection of the boron precursor) has already been studied previously, ${ }^{18}$ and it has been, in particular, demonstrated that atomic nitrogen can be produced at relatively low gas temperatures $(\sim 400 \mathrm{~K})$ with this plasma source. Moreover, it has been shown that the gas mixture should give the best compromise between the production of atomic nitrogen and the lifetime of the device, which is $50 \%$ of $\mathrm{Ar}$ and $50 \%$ of $\mathrm{N}_{2}$.

The results presented in this Letter demonstrate the feasibility of h-BN synthesis using MHCD in a reactive gas mixture at temperatures substantially lower than those reported in the literature $\left(800^{\circ} \mathrm{C}\right.$ instead of $\left.\sim 1300^{\circ} \mathrm{C}\right) .{ }^{19,20}$ The choice of the substrate depends strongly on the 
application, and for that reason, we have chosen 2-in. Si substrates with native oxide, which avoid a mechanical exfoliation transfer step from other substrates to silicon ones.

The microplasma reactor developed for the deposition of $\mathrm{h}-\mathrm{BN}$ is illustrated in Fig. 1. The reactor is composed of two chambers maintained at different pressures. The MHCD plasma source is located at the junction between those two chambers and is continuously fed with an $\mathrm{Ar} / \mathrm{N}_{2}$ mixture (50\% of $\mathrm{Ar}$ and $50 \%$ of $\mathrm{N}_{2}$ ), which is injected in chamber 1 . The plasma source consists of an anode-dielectric-cathode stack through which one hole with a diameter of $400 \mu \mathrm{m}$ is drilled. The higher pressure chamber (chamber 1 in Fig. 1; 35 mbar) favors the production of a high density plasma, and, consequently, a high $\mathrm{N}_{2}$ dissociation is expected. The lower pressure chamber (chamber 2 in Fig. 1; 0.7 mbar) limits atomic nitrogen recombination, thus providing enough $\mathrm{N}$ atoms for the targeted application of this work.

The first deposition tests using this MHCD-based process have been performed using only one hole to have a system as simple as possible. In the future, we plan to use arrays of MHCDs ${ }^{18}$ to increase the plasma volume and study the impact on film uniformity. Serious attention has to be paid to the voltage waveform applied to the MHCD source. In fact, microdischarge arrays are subject to thermal instabilities, followed by the glow-to-arc transition at high current density. One solution to overcome this problem is to pulse the discharge at high repetition frequency. For that reason, the MHCD is ignited by applying nanosecond high-voltage pulses $(1 \mathrm{kV}$ amplitude, $500 \mathrm{~ns}$ width, and $10 \mathrm{kHz}$ repetition frequency) to the first electrode (i.e., the cathode in chamber 1), with the other electrode (the anode located in chamber 2) being grounded. More details on the homemade power supply used for the deposition process can be found in the study by Kasri et al. ${ }^{18}$ The discharge is ignited inside the micro-hole and forms a jet in chamber 2 due to the pressure difference between the two chambers. The polarizable and heated substrate holder is located in the lower pressure chamber where the boron precursor is injected. The polarization of the substrate holder by a DC positive voltage allows the discharge to expand from the micro-hole to the substrate, as illustrated in Fig. 1. The distance between the substrate holder and the plasma

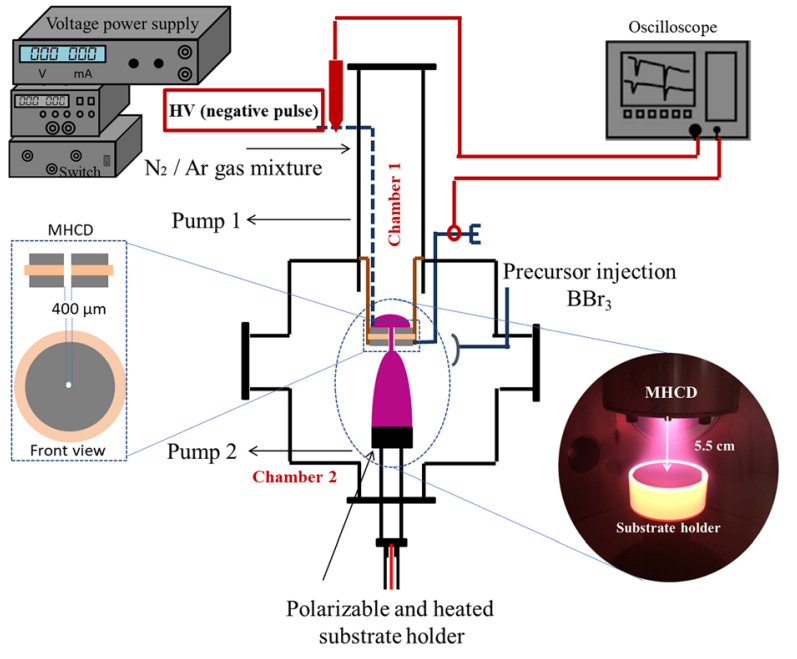

FIG. 1. Experimental setup. source is fixed at $5.5 \mathrm{~cm}$. It should be noted that, despite having only one hole, the plasma covers the entire surface of the 2 -in. wafer.

After heating up the substrate under a flux of $\mathrm{N}_{2}$ to reach a growth temperature of $800^{\circ} \mathrm{C}$, the microplasma is ignited in the MHCD structure using gas flows of $50 \mathrm{sccm}$ of Ar and $50 \mathrm{sccm}$ of $\mathrm{N}_{2}$. The substrate holder is then polarized with a DC positive voltage of $230 \mathrm{~V}$. Under our experimental conditions, the average discharge current is $0.3 \mathrm{~A}$ and the energy deposited in the plasma is $71 \mu \mathrm{J}$. These conditions are maintained for $10 \mathrm{~min}$ before injecting the boron precursor into chamber 2 at a flow rate of $2 \mu \mathrm{mol} / \mathrm{min}$ using a bubbler cylinder maintained at a temperature of $5^{\circ} \mathrm{C}$. The thin h-BN film is then grown for several hours ( 2 and $7 \mathrm{~h}$ in this paper) on a 2 -in. (100) silicon substrate before the heater, the plasma and the precursor flows are all simultaneously switched off to cooldown to room temperature.

The growth temperature is monitored at the surface of the substrate holder by a two-color pyrometer throughout the whole experimental process, and the growth rate is measured at the substrate center by in situ interferometry. At the end of the deposition process, the films are characterized by Raman spectroscopy (Jobin-Yvon HR800), TEM (Transmission Electron Microscopy), and EELS (Electron Energy Loss Spectroscopy) performed using a JEOL JEM 2010.

The image of the film obtained by a 2 -h deposition is presented in Fig. 2(a). It shows that the deposited film covers almost all the surface of the 2-in. Si substrate. Nevertheless, we can note some inhomogeneities of color and texture. In particular, we observe some holes, which correspond to areas where no layer of $\mathrm{BN}$ has been deposited, and straight lines at different places of the film. The change in film color (from the center to the edge: dark yellow, yellow, gray, and transparent gray, respectively) is related to the change in the thickness, which can be explained by a slight temperature gradient at the surface of the substrate from the center to the edge. The calculated growth rate is $30 \mathrm{~nm} / \mathrm{h}$.

The corresponding Raman spectrum, obtained one day after the synthesis and recorded with an excitation laser line at $473 \mathrm{~nm}$, is presented in Fig. 2(b) (see the black curve). It exhibits a clear signature of the $\mathrm{E}_{2 g}$ vibration mode of $\mathrm{h}-\mathrm{BN}^{21-23}$ at $1362 \mathrm{~cm}^{-1}$, which is an indication that this $\mathrm{MHCD}$ process can be used to deposit hexagonal boron nitride.

The theoretical value of the average crystallite size, $\mathrm{L}_{\mathrm{a}}$, can be deduced from the full width at half maximum (FWHM), $\Gamma_{1 / 2}$, of the Raman line using the following equation: ${ }^{24}$

$$
\Gamma_{1 / 2}\left(\mathrm{~cm}^{-1}\right)=8.7 \mathrm{~cm}^{-1}+1417 \mathrm{~cm}^{-1} / L_{a}(\AA) .
$$

The FWHM deduced from Fig. 2(b) is $55 \mathrm{~cm}^{-1}$, which corresponds to a domain size of about $3 \mathrm{~nm}$. This small lateral size of h-BN domains may be caused by the random and uncontrolled nucleation of this material on $\mathrm{SiO}_{2} / \mathrm{Si}$ substrates.

The broad Raman line and the small related domain size indicate a moderate crystalline quality (disordered h-BN phase). This is possibly due to the moderate deposition temperature compared to conventional processes (up to $\left.1300^{\circ} \mathrm{C}\right)^{19,20}$ and to the fact that the deposition conditions are not yet optimized.

EELS analyses have also been carried out. The result obtained 1 day after synthesis for a 2 -h deposition is presented in Fig. 3(a) (see the black line). The spectrum at the boron k-edge confirms the presence of boron and nitrogen signatures. The chemical composition 
(a)
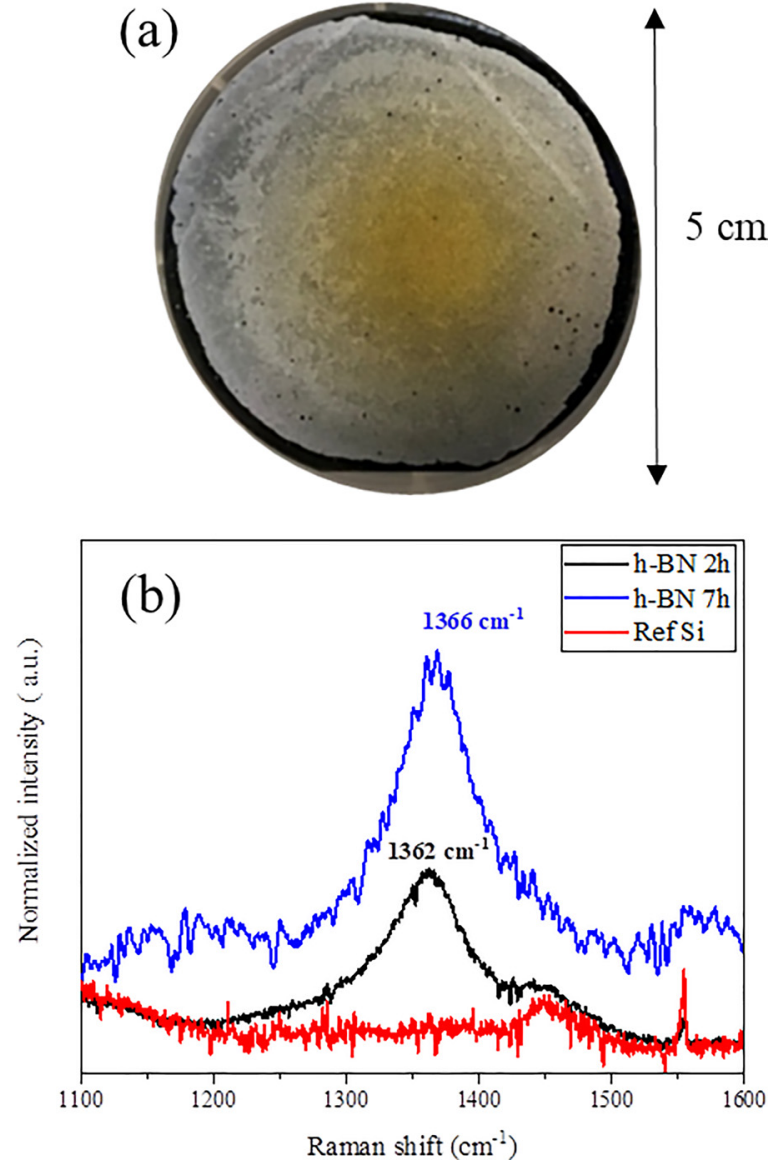

FIG. 2. (a) Image of the h-BN film obtained by a 2-h deposition and (b) Raman spectra of h-BN films obtained by a 2-h (in black) and a 7-h (in blue) deposition (the $\mathrm{Si}$ reference spectrum is given in red).

is quantified from EELS measurements and demonstrates close concentrations of both elements: 56 at. $\%$ of B and 44 at. $\%$ of $\mathrm{N}$.

Nevertheless, color degradation of the films is observed after a few days of exposure to ambient air because of the increasing oxidation of the film over time. EELS measurements made on a sample 14 days after the film synthesis confirm this degradation by revealing the presence of oxygen [see the red line in Fig. 3(a)] at a high concentration: 44 at. \% of $\mathrm{B}, 23$ at. $\%$ of $\mathrm{N}$, and 33 at. \% of $\mathrm{O}$. A recent study dedicated to h-BN films exposed to air has shown a similar behavior. According to the authors, oxygen could diffuse through the grain boundaries of the $\mathrm{BN}$ stack. ${ }^{26}$

It has been shown in the literature that longer deposition times can lead to a stack of different layers, with a first layer of the disordered h-BN phase underneath the h-BN layer. ${ }^{28}$ This indicates that the growth of h-BN requires the formation of a buffer layer prior to its nucleation. The tested deposition duration may not be sufficient for the nucleation of h-BN (as also suggested by the small domain size obtained from the Raman spectrum), and that is why some tests have then been performed for a higher deposition duration of $7 \mathrm{~h}$.

The Raman spectrum of the film obtained after $7 \mathrm{~h}$ of deposition [see the blue curve in Fig. 2(b)] also exhibits the signature of the $\mathrm{E}_{2 g}$
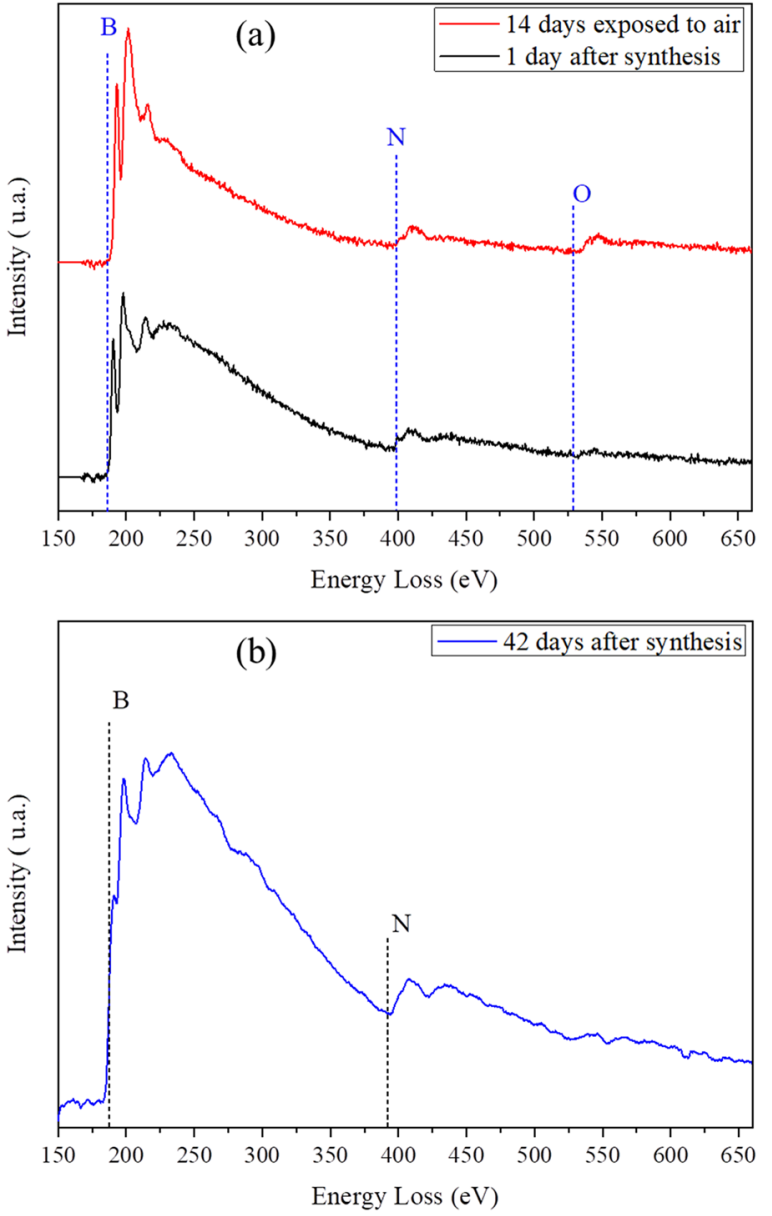

FIG. 3. EELS spectra of $h-B N$ particles suspended on the holey $C$ film: (a) for a $2-h$ deposition, 1 day (in black) and 14 days (in red) after synthesis, and (b) for a 7-h deposition, 42 days after synthesis.

vibration mode of h-BN, but with a slightly lower half width at half maximum, indicating a slightly better crystallinity as the deposition duration increases. It can also be noted that the peak intensity associated with the 7-h deposition layer is higher than that of the 2-h deposition layer, indicating that the former layer is thicker than the latter. Furthermore, the EELS results presented in Fig. 3(b) show that there is no degradation of the film with time, with no oxygen being detected in the film even 42 days after the synthesis. This demonstrates that h-BN is deposited when the MHCD deposition process is carried out for $7 \mathrm{~h}$.

A cross-sectional lamella of the 7-h deposition film has been prepared by focused ion beam (FIB) in order to deeply investigate the layer growth of BN by means of high resolution TEM. The results are presented in Fig. 4. The micrograph presented in Fig. 4(a) shows that only one layer of boron nitride has grown with a thickness of $250 \mathrm{~nm}$ and that the thickness of the $\mathrm{SiO}_{2}$ layer on the $\mathrm{Si}$ substrate is about $40 \mathrm{~nm}$, which is quite large. The corresponding high resolution micrograph presented in Fig. 4(b) shows that the lateral size of h-BN domains is quite small, about $3 \mathrm{~nm}$, which is in good agreement with the value deduced from the Raman spectrum [theoretical calculation 

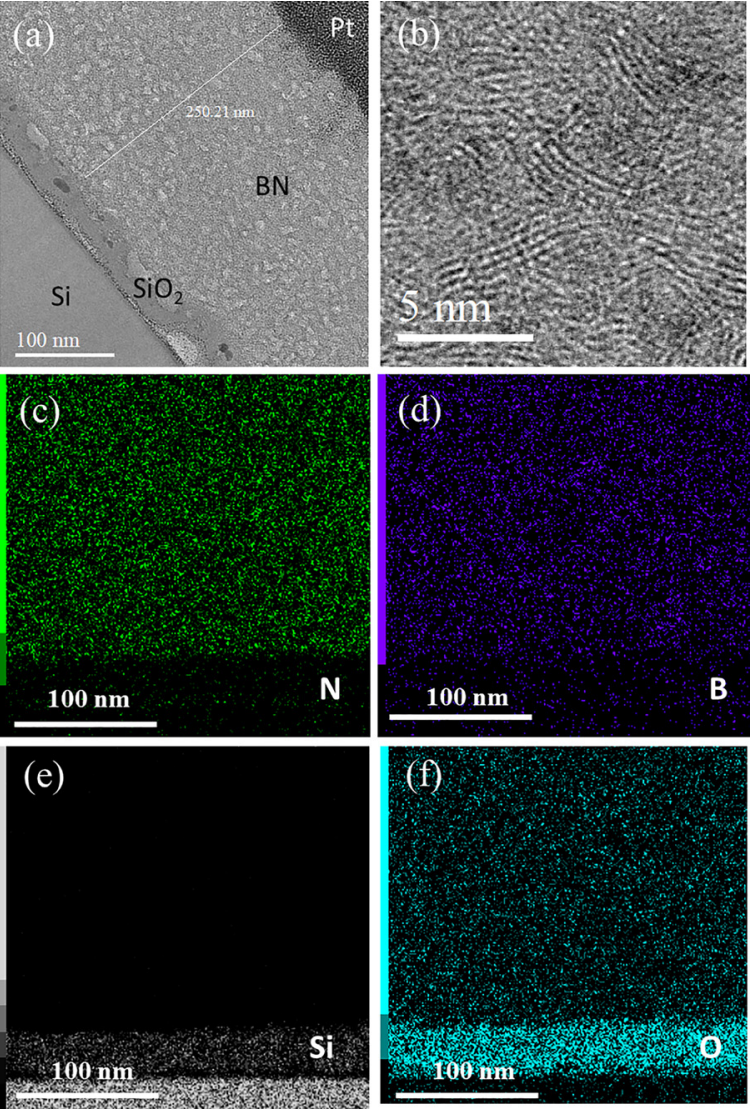

FIG. 4. (a) Micrograph of a cross-sectioned h-BN film deposited on a $\mathrm{SiO}_{2} / \mathrm{Si}$ substrate and (b) the corresponding high-resolution micrograph. X-mapping of (c) nitrogen, (d) boron, (e) silicon, and (f) oxygen.

from Eq. (1)]. The micrographs obtained from Energy Dispersive $\mathrm{X}$-ray Spectroscopy (EDS) mapping analyses reveal a homogeneous distribution of nitrogen [see Fig. 4(c)] and boron [see Fig. 4(d)] atoms in the film. This is in agreement with the previously presented EELS results, showing a ratio of B over $\mathrm{N}$ close to unity. Figures 4(e) and 4(f) confirm that the layer between the substrate and the $\mathrm{BN}$ layer is a $40 \mathrm{~nm}$ thick layer of $\mathrm{SiO}_{2}$. The growth of this layer is due to the presence of oxygen in the deposition chamber. The $\mathrm{SiO}_{2}$ layer is neither uniform nor pure (see Fig. S2, showing the bright field TEM micrograph, in the supplementary material). We also observe some microparticles in this layer corresponding to heavy elements. More precisely, there is a molybdenum contamination (see the Mo-L map of Fig. S2) coming from the microplasma source and/or the heated substrate holder and a slight carbon contamination (few atom\%) coming from the heating element in graphite of the substrate holder (see Figs. S1 and S2 in the supplementary material). This slight carbon contamination is also present in the h-BN layer (see the C-K map of Fig. S2).

To conclude, a MHCD-based process was used for the deposition of hexagonal boron nitride, a material known for its outstanding properties and its compatibility with $2 \mathrm{D}$ materials such as graphene or transition metal dichalcogenides. The nitrogen and boron atoms are produced at lower temperature than those of the conventional deposition processes by the dissociation of $\mathrm{N}_{2}$ in the MHCD and the use of $\mathrm{BBr}_{3}$ as a precursor. h-BN thin film synthesis on 2-in. Si substrates has been achieved using only one MHCD, which is proof of the feasibility of material deposition on large areas by this microplasma process.

Raman spectroscopy shows a clear signature of h-BN films. EELS analyses demonstrate that $\mathrm{B}$ and $\mathrm{N}$ atoms are present at very close concentrations in the deposited films as expected for a stoichiometric material. For a 2-h deposition, a degradation of the films is observed after a few days of exposure to ambient air, which could be due to a diffusion of oxygen into the grain boundaries of the films (disordered $\mathrm{h}-\mathrm{BN}$ phase). An increase in the deposition duration from 2 to $7 \mathrm{~h}$ allows for the synthesis of stable films (hexagonal BN), with a homogeneous distribution of boron and nitrogen atoms in the films.

The plasma and growth conditions will be varied to optimize the quality of the deposited BN films. Nevertheless, this study paves the way for the fabrication of this strategic material directly on a large area semiconducting substrate at lower temperatures in comparison with conventional deposition processes.

See the supplementary material for the Energy Dispersive X-ray spectrum of the layer between the Si substrate and the deposited layer of $\mathrm{BN}$ as well as the bright field Transmission Electron Microscopy micrographs of the h-BN film on the silicon substrate and the corresponding X-mapping of the different elements.

This work was supported by the French Research National Agency (ANR) through the DESYNIB Project (No. ANR-16CE080004 JCJC), the CNRS Technological Network CRISTECH, and the Labex SEAM. The authors would like to thank Ludovic William, Nicolas Fagnon, and Noel Girodon-Boulandet from the LSPM laboratory in Paris for their technical support, Michel Fleury from the LPGP laboratory in Orsay for the development and fabrication of the high voltage power supply as well as the Jean Lamour Institute for the characterization by high resolution transmission electron microscopy of the deposited films.

\section{REFERENCES}

'Y. Kobayashi, K. Kumakura, T. Akasaka, and T. Makimoto, Nature 484, 223 (2012).

${ }^{2}$ M. Chubarov, H. Pedersen, H. Hogberg, S. Filippov, J. A. A. Engelbrecht, J. O'Connel, and A. Henry, Physica B 439, 29 (2014).

${ }^{3}$ A. Pakdel, Y. Bando, and D. Golberg, Chem. Soc. Rev. 43, 934 (2014).

${ }^{4}$ P. Bhauriyal, G. Bhattacharyya, K. S. Rawat, and B. Pathak, J. Phys. Chem. C 123(7), 3959 (2019).

${ }^{5} \mathrm{H}$. Wang, T. Taychatanapat, A. Hsu, K. Watanabe, T. Taniguchi, P. Jarillo-Herrero, and T. Palacios, IEEE Electron Device Lett. 32(9), 1209 (2011).

${ }^{6}$ K. H. Lee, H.-J. Shin, J. Lee, I.-Y. Lee, G.-H. Kim, J.-Y. Choi, and S.-W. Kim, Nano Lett. 12(2), 714 (2012).

${ }^{7}$ N. Patibandla and K. L. Luthra, J. Electrochem. Soc. 139, 3558 (1992).

${ }^{8}$ Z. Xu, H. Tian, A. Khanaki, R. Zheng, M. Suja, and J. Liu, Sci. Rep. 7, 43100 (2017)

${ }^{9}$ H. Tian, A. Khanaki, P. Das, R. Zheng, Z. Cui, Y. He, W. Shi, Z. Xu, R. Lake, and J. Liu, Nano Lett. 18, 3352 (2018).

${ }^{10}$ M. Weber, B. Koonkaew, S. Balme, I. Utke, F. Picaud, I. Iatsunskyi, E. Coy, P. Miele, and M. Bechelany, ACS Appl. Mater. Interfaces 9(19), 16669 (2017).

${ }^{{ }^{11}}$ T. Baazi and E. J. Knystautas, Thin Solid Films 232(2), 185 (1993). 
${ }^{12}$ E. Stoffels, A. J. Flikweert, W. W. Stoffels, and G. M. W. Kroesen, Plasma Sources Sci Technol. 11, 383 (2002).

${ }^{13}$ R. Sankaran, K. P. Giapis, M. Moselhy, and K. H. Schoenbach, Appl. Phys. Lett. 83, 4728 (2003).

${ }^{14}$ T. Nozaki, K. Sasaki, T. Ogino, D. Asahi, and K. Okazaki, Nanotechnology 18, 235603 (2007).

${ }^{15}$ K. H. Schoenbach, R. Verhappen, T. Tessnow, F. E. Peterkin, and W. W. Byszewski, Appl. Phys. Lett. 68, 13 (1996).

${ }^{16}$ C. Lazzaroni, P. Chabert, A. Rousseau, and N. Sadeghi, Eur. Phys. J. D 60, 555-563 (2010).

${ }^{17}$ C. Lazzaroni and P. Chabert, J. Appl. Phys. 111, 053305 (2012).

${ }^{18}$ S. Kasri, L. William, X. Aubert, G. Lombardi, A. Tallaire, J. Achard, C. Lazzaroni, G. Bauville, M. Fleury, K. Gazeli, S. Pasquiers, and J. S. Sousa, Plasma Sources Sci. Technol. 28, 035003 (2019).

${ }^{19}$ Y.-J. Cho, A. Summerfield, A. Davies, T. S. Cheng, E. F. Smith, C. J. Mellor, A. N. Khlobystov, C. T. Foxon, L. Eaves, P. H. Beton, and S. V. Novikov, Sci. Rep. 6, 34474 (2016).

${ }^{20}$ H. X. Jiang and J. Y. Lin, Semicond. Sci. Technol. 29, 084003 (2014).
${ }^{21}$ S. Y. Bae, H. W. Seo, J. Park, Y. S. Choi, J. C. Park, and S. Y. Lee, Chem. Phys. Lett. 374, 534 (2003).

${ }^{22}$ S. Nakhaie, J. M. Wofford, T. Schumann, U. Jahn, M. Ramsteiner, M. Hanke, J. M. J. Lopes, and H. Riechert, Appl. Phys. Lett. 106, 213108 (2015).

${ }^{23}$ P. Sutter, J. Lahiri, P. Zahl, B. Wang, and E. Sutter, Nano Lett. 13, 276 (2013).

${ }^{24}$ R. J. Nemanich, S. A. Solin, and R. M. Martin, Phys. Rev. B 23, 6348 (1981).

${ }^{25}$ Y. Tay, S. H. Tsang, M. Loeblein, W. L. Chow, G. C. Loh, J. W. Toh, S. L. Ang, and E. H. T. Teo, Appl. Phys. Lett. 106, 101901 (2015).

${ }^{26}$ L. Jiang, N. Xiao, B. Wang, E. Grustan-Gutierrez, X. Jing, P. Babor, M. Kolibal, G. Lu, T. Wu, H. Wang, F. Hui, Y. Shi, B. Song, X. Xie, and M. Lanza, Nano Res. 10(6), 2046 (2017).

${ }^{27}$ M. S. Bresnehan, M. J. Hollander, M. Wetherington, K. Wang, T. Miyagi, G. Pastir, D. W. Snyder, J. J. Gengler, A. A. Voevodin, W. C. Mitchel, and J. A. Robinson, J. Mater. Res. 29(3), 459 (2014).

${ }^{28}$ K. Sankaran, D. Hoang, S. Kunuku, S. Korneychuk, S. Trner, P. Pobedinskas, S. Drijkoningen, M. K. V. Bael, J. D. Haen, J. Verbeeck, K. Leou, I. Lin, and K. Haenen, Sci. Rep. 6, 29444 (2016). 